\title{
A (não) noticiabilidade da CPLP no Brasil: Jornalismo, memórias e identidades
}

\author{
José Cristian Góes \\ Universidade Federal de Minas Gerais \\ cristiangoes_brasil@yahoo.com.br \\ Elton Antunes \\ Universidade Federal de Minas Gerais \\ eltunes@uol.com.br
}

\begin{abstract}
Resumo
Discutimos como memória, história e identidades atravessam sutilmente o jornalismo. Partimos da compreensão de que o jornalismo é agente de memória e que busca, tanto no passado quanto na projeção, sentidos inteligíveis do mundo (Zelizer, 2008). Se o lembrar e o esquecer são resultados de tensões a ganhar à superfície entre as notícias, discutimos em que medida eles aparecem ou não abrigados nos critérios do noticiável. Ao se investigar os registros nos jornais nos jornais brasileiros Folha de S. Paulo e O Globo sobre a Comunidade dos Países da Língua Portuguesa (CPLP), nos dez primeiros anos dessa entidade, percebemos a sua "não-noticiabilidade", marcada por silenciamento, por uma memória ocultada, em que o Brasil busca não ser associado a uma comunidade de países majoritariamente pobre e negra.
\end{abstract}

Palavras-chave: Jornalismo; noticiabilidade; memória; identidade; CPLP

\begin{abstract}
We discussed how memory, history and identity subtly pass through journalism. We start from the understanding that journalism is memory agent that seeks both past and the projection intelligible way the world (Zelizer, 2008). So, remember and forget are the result of tensions that come to the surface of the news, to what extent they appear or not housed in reportable criteria. To investigate whether the records in the Brazilian newspaper Folha de S. Paulo and $O$ Globo on the Community of the Portuguese Speaking Countries (CPLP), in the first ten years of the creation of this body, we realized a non-newsworthiness, marked by silencing by a memory hidden, in which Brazil seeks to not be associated with a largely poor and black community.
\end{abstract}

Keywords: Journalism; newsworthiness; memory; identity; CPLP

\section{Jornalismo, noticiabilidade e CPLP}

Parte dos estudos do Jornalismo se movimenta num confuso labirinto de ideias. Buscam- 
se o conceito de notícia, discutem-se os acontecimentos, o papel dos jornalistas, as relações com as fontes, a influência junto ao público, entre outras questões. Uma das indagações recorrentes é saber como a notícia é selecionada, o porquê raras ocorrências são noticiáveis e, a maioria, não. Nas teses sobre o jornalismo há, por exemplo, a ideia de noticiabilidade, um conjunto de critérios aplicados a eventos que possibilitam definir se um fato será ou não uma notícia. Os especialistas, aqueles que dominam técnicas e práticas pré-estabelecidas vão, de forma quase automática, selecionar a notícia num emaranhado de atos públicos e privados e, se escolhido como notícia, o acontecimento era "relevante, próximo, atual". Gislene Silva (2014) sintetiza os critérios de noticiabilidade como

"todo e qualquer fator potencialmente capaz de agir no processo de produção da
notícia, desde características do fato, julgamentos pessoais dos jornalistas, cultura
profissional da categoria, condições favorecidas ou limitantes da empresa de mídia,
qualidade do material (imagem e texto), relação com as fontes e com o público,
fatores éticos e ainda circunstâncias históricas, políticas, econômicas e sociais" (Silva,
2014: 52).

Essas definições acabam apoiando-se num viés operativo de jornalismo, onde a notícia é vista como "um artefato social, algo (uma informação via discurso, texto, vídeo ou foto) que viaja de uma pessoa (ou de uma organização) para um único - ou para múltiplos receptor/receptores" (Shoemaker, 2014: 15). Reforça-se, assim, uma cadeia transmissiva de informações, onde as partes do complexo comunicacional parecem apartadas e em lugares fixos. Esse script de critérios pressupõe, na prática, uma rotina estável. Mas isso, de fato, ocorre no jornalismo? Noticiabilidade dá conta das múltiplas realidades do jornalismo ou é, em larga medida, simplificadora delas?

Sugerimos que os parâmetros do noticiável não conseguem abrigar as negociações, as tensões das relações de poder, os fenômenos sutis que atravessam o jornalismo. Isso porque a notícia emerge nas e das relações sociais, ou seja, em um ambiente assimétrico e instável. Franciscato (2014: 87) reconhece a condição redutora dos critérios de noticiabilidade, em especial quando eles acentuam "aspectos isolados de um fato". Esse autor lembra que o jornalismo está imerso num contexto espaço-temporal, vinculado a processos sócio-históricos. Assim, estabelecer regras do que será ou não notícia pode implicar em negligenciar os atravessamentos nascidos nas relações sociais, como os da memória, história e identidades.

Nesse texto, propomo-nos perceber a memória em meio ao processo noticioso, não como critério, mas como algo que perpassa o jornalismo. E isso porque as relações abrigam tensões não-visíveis que se refletem entre o que será lembrado e o que será esquecido. A notícia emerge como lembrança, mas "tão importante quanto entender o que recordamos, é compreender porque e como recordamos determinados acontecimentos e esquecemos de outros" (Cabecinhas, 2006: 6).

Entendemos o jornalismo como experiência relacional, em que a notícia não é apenas um produto construído em esteiras industriais, resultado da aplicação de fórmulas. Ela é um "estado 
sempre nascente, revivida a cada momento no mundo da vida onde os sujeitos, tanto quanto a percepção, são construídos pela própria experiência" (Motta, 2014: 9). As notícias são textos vivos a produzir interpretações e a convocar temporalidades e historicidades. Elas são parte de uma confusa teia de relações que se entrelaça a outras incontáveis teias, sempre apontando para fora dos quadros propostos, buscando múltiplas conexões, inclusive além do jornalismo.

Além disso, o jornalismo está implicado no mundo, sendo operador sócio-simbólico que age em conjunto com outros operadores e que o público remaneja os sentidos propostos por ele, recolocando-os em seus ambientes culturais (Mouillaud, 1997). Assim, ele não se explica apenas por organizações e por seus modos de fazer. Empresas, jornalistas e fontes não são a gênese absoluta da notícia. A relevância de um acontecimento será construída nas relações que se tecem, fazendo-se memória, configurando-se notícia. Relevância "surge em reverberação, junto com uma experiência publicamente acessada e compartilhada" (Mafra, 2014: 107).

Analisamos nesse artigo os registros nos jornais brasileiros Folha de S. Paulo e O Globo sobre as nações dos povos de língua portuguesa, reunidos na Comunidade dos Países de Língua Portuguesa (CPLP). Investigamos como esses jornais noticiaram os dez primeiros anos dessa entidade. O levantamento ocorreu nas edições de $1^{\circ}$ de janeiro de 1996 a $1^{0}$ de janeiro de 2006. Os países membros e efetivos da CPLP são: Angola, Cabo Verde, Guiné Bissau, Guiné Equatorial, Moçambique e São Tomé e Príncipe, na África; o Brasil, na América do Sul; Portugal, na Europa; e Timor Leste, na Ásia. Neles, o idioma oficial é o português e a língua comum é o principal laço e argumento comunitário da CPLP.

Contudo, a comunidade lusófona tem raízes mais profundas. Entre seus países, os elos sócio-históricos os entrelaçam, estabelecendo identidades. Por exemplo, Portugal foi metrópole dessas nações, e o Brasil se constituiu, em grande parte, com suor e sangue dos escravos das colônias luso-africanas. Em 1986, o Rio de Janeiro sediou o Encontro de Unificação Ortográfica da Língua, e a criação da CPLP, em 1996, foi resultado da ação direta do ex-embaixador brasileiro José Aparecido. Há um histórico de cooperação entre seus governos. Por exemplo, em 2011, foi criada a Universidade da Integração Internacional da Lusofonia Afro-Brasileira (Unilab). Ela tem sede no Ceará, no Brasil, e metade das vagas é destinada aos países da CPLP.

A Folha de $S$. Paulo e $O$ Globo foram escolhidos nessa investigação porque biscam ter abrangência nacional e têm as maiores circulações no Brasil ${ }^{49}$. A Folha, por exemplo, tem como slogan "Um jornal a serviço do Brasil". Já O Globo faz parte de um dos maiores grupos de comunicação do mundo, as Organizações Globo. Os dois jornais têm histórias ligadas aos maiores grupos econômicos do Brasil, fazem parte de complexos de mídia e possuem amplas parcerias internacionais, principalmente nos Estados Unidos. Arbex Jr. (2001) diz esses jornais são empresas capitalistas com o interesse no lucro e poder. Suas produções jornalísticas sempre são voltadas para a defesa e a promoção do capital financeiro e da máxima redução do Estado, apresentando-se como porta-vozes dos "interesses da nação". Eles adotam um "discurso-para-

49 Dados da Associação Brasileira dos Jornais (ABJ), em 2014, o jornal Folha de S. Paulo teve a maior média mensal de circulação, com 351.745 jornais, seguido de $O$ Globo com 333.860 edições. 
o-mercado como estratégia empresarial e editorial" (Arbex Jr., 2001: 141), que estabelece o desenvolvimento norte-americano e eurocêntrico como padrão a seguir e, ao mesmo tempo, estigmatiza e excluí qualquer traços de subdesenvolvimento.

\section{Outra visada do jornalismo: o enxergar de comunidades}

A partir da investigação no acervo dos jornais encontramos somente 38 registros sobre a CPLP na Folha de S. Paulo (Tabela 1) e 50 em O Globo (Tabela 2) no período de dez anos. Como nosso objetivo é conhecer a ação direta e intencional dos jornais sobre a CPLP, definimos a categoria registros que abriga notícias, reportagens, entrevistas e editoriais. Foram excluídos os artigos de opinião, notinhas em colunas, cartas do leitor, editais e anúncios de publicidade.

Realizada essa triagem, os registros foram agrupados por anos e temas em quatro grupos, no sentido de "fato crucial" ou evento-chave (Ettema \& Glasser, 2011): ações relativas ao presidente Fernando Henrique Cardoso (FHC), de 1996 a 2002; ações do presidente Luiz Inácio Lula da Silva, de 2003 a 2006; registros de acordos (ortográfico, saúde e outros); e registros de conflitos (golpes, guerras civis).

Tabela 1 - Registros na Folha de S. Paulo sobre a CPLP

\begin{tabular}{|l|c|c|c|c|c|c|c|c|c|c|c|}
\hline Anos & 1996 & 1997 & 1998 & 1999 & 2000 & 2001 & 2002 & 2003 & 2004 & 2005 & TOTAL \\
\hline $\begin{array}{l}\text { Criterios } \\
\text { Fresidente }\end{array}$ & 05 & - & 01 & 01 & 01 & - & 02 & - & - & - & 10 \\
\hline $\begin{array}{l}\text { Presidente } \\
\text { Lula }\end{array}$ & - & - & - & - & - & - & - & 04 & 04 & - & 08 \\
\hline $\begin{array}{l}\text { Acordos } \\
\text { CPLP }\end{array}$ & 03 & 01 & 02 & 01 & - & 02 & 01 & 01 & 02 & - & 13 \\
\hline Conflitos & 01 & - & 04 & - & 02 & - & - & - & - & - & 07 \\
\hline SUBTOTAL & 09 & 01 & 07 & 02 & 03 & 02 & 03 & 05 & 06 & 00 & 38 \\
\hline
\end{tabular}

Fonte: pesquisa no acervo do jornal de $1^{\circ}$ de janeiro de 1996 a $1^{\circ}$ de janeiro de 2006

Tabela 2 - Registros em O Globo sobre a CPLP

\begin{tabular}{|l|c|c|c|c|c|c|c|c|c|c|c|}
\hline AnOS & 1996 & 1997 & 1998 & 1999 & 2000 & 2001 & 2002 & 2003 & 2004 & 2005 & TOTAL \\
\hline $\begin{array}{l}\text { Criterios } \\
\text { Fresidente }\end{array}$ & 04 & - & - & - & 02 & - & 01 & - & - & - & 07 \\
\hline $\begin{array}{l}\text { Presidente } \\
\text { Lula }\end{array}$ & - & - & - & - & - & - & - & - & 04 & 02 & 06 \\
\hline $\begin{array}{l}\text { Acordos } \\
\text { CPLP }\end{array}$ & 05 & 04 & 03 & 02 & 02 & 02 & 02 & 01 & 02 & 02 & 25 \\
\hline $\begin{array}{l}\text { Confiltos } \\
\text { SUBtOTAL }\end{array}$ & 01 & - & 04 & 05 & 01 & - & - & 01 & - & - & 12 \\
\hline
\end{tabular}

Fonte: pesquisa no acervo do jornal de $1^{\circ}$ de janeiro de 1996 a $1^{\circ}$ de janeiro de 200

De saída, constamos a irrelevante quantidade de registros nos dois jornais em dez anos da CPLP. As poucas notícias se diluíram, perdendo-se por entre 7.300 edições nesses periódicos em todo período. Na prática, é como se essa comunidade não existisse. Em O Globo, em média, 
foram apenas de 5 registros por ano. Na Folha, somente 3,8.

Quando os dois jornais trataram da CPLP, o grupo acordo foi preponderante, muito em razão da proposta de unificação da escrita nos países da comunidade, mas não só por isso. Ao todo foram 13 registros na Folha e 25 em O Globo. Sugerimos uma relação com a ideia política brasileira de tutelar os destinos dos países africanos, que até se assemelha a ação neocolonial, e que visa receber o apoio dessas nações para uma vaga ao Brasil no Conselho de Segurança da ONU. Além disso, enfocar em acordos pode tirar o peso da dívida que o Brasil tem para com a África. No caso de $O$ Globo, o interesse atende a ampliação do mercado de mídia.

$\mathrm{Na}$ análise dos dados, vale observar os registros dos presidentes. Na Folha, foram 10 anotações envolvendo FHC. O presidente Lula recebeu 8 registros nesse jornal. Em $O$ Globo, as notícias com FHC foram 7 e, com Lula, 6. Entretanto, é preciso lembrar que no período dos dez anos, sete foram no Governo FHC e três no de Lula, revelando maior intensidade nos primeiros anos do presidente Lula. Há uma ação mais incisiva de Lula junto a CPLP, realizando um trânsito maior com África, diferente do que ocorreu com o presidente FHC. Na apuração mais detalhada, percebemos ainda a concentração dos registros. Na Folha, de 10 registros de FHC, 5 foram em 1996, sendo que 4 deles são de 14 a 18 de julho, em razão da viagem do presidente para a criação da CPLP. Depois, a temática só reaparece numa pequena notícia em 1998. Com Lula, em 2004, esse jornal publicou 4 notícias, sendo que todas foram de 21 a 28 de julho, em razão da viagem de Lula à África. Na sequência, há silêncio, incluindo todo ano de 2005.

No ano 2000 foram lembrados os 500 anos do Brasil. Ano marcado por ações de celebração e de protestos. Mas, nem a Folha e nem $O$ Globo inseriram os países dessa comunidade nas coberturas da efeméride. Não é preciso lembrar que as nações da CPLP estão diretamente envolvidas com os 500 anos. No entanto, naquele ano há somente 3 registros na Folha e 5 em Globo e sem relação direta com os 500 anos.

Independentemente das relações históricas e identitárias entre os países dessa comunidade, a CPLP, enquanto instituição, não teria uma agenda que merecesse ser noticiada no Brasil? Em documento oficial dessa entidade, intitulado "18 anos CPLP: os desafios do futuro" (ILHARCO \& MURARGY, 2014) estão relacionadas atividades realizadas, ano a ano, como missões diplomáticas e encontros envolvendo os países membros. No período dos dez anos foram anotados 151 atos oficiais. Em 2005, por exemplo, enquanto a CPLP teve 29 eventos (Quadro 1), na Folha não há registro relacionado à comunidade. Nem quando o Brasil comandou a CPLP (2000 e 2001), houve noticiabilidade. Nesses dois anos foram registradas 27 ações na CPLP. Em O Globo foram 7 registros, e na Folha, apenas 5 no período (Tabela 3). 


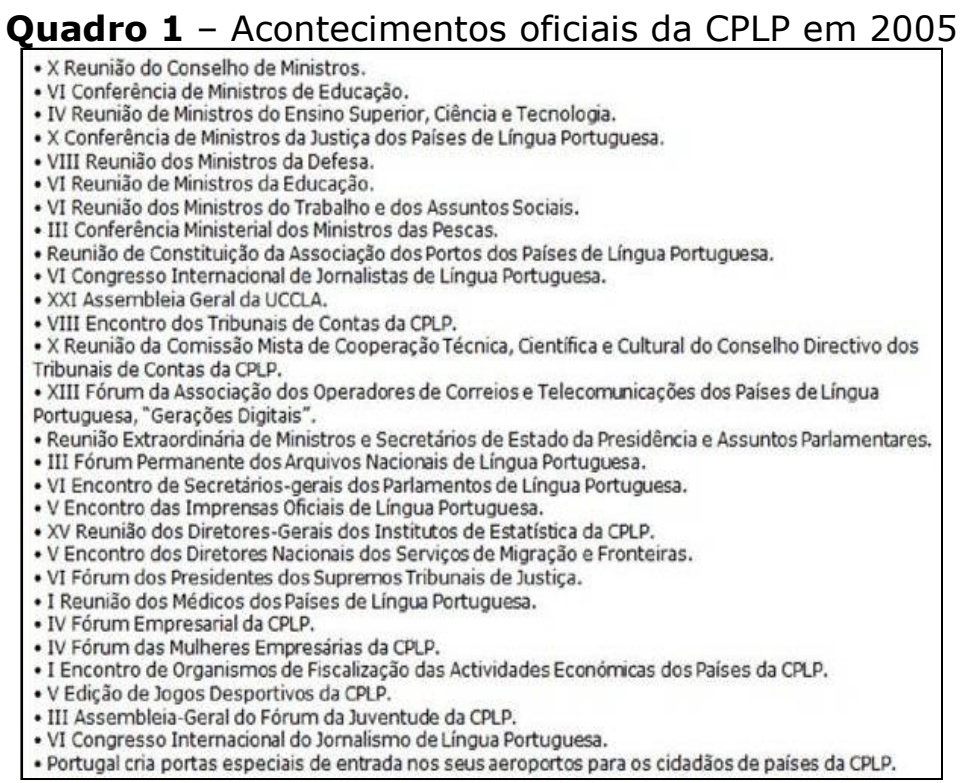

Fonte: 18 anos CPLP: os desafios do futuro (2014, p. 154-155)

Tabela 3 - Comparação entre atos oficiais da CPLP e os registros nos jornais

\begin{tabular}{|c|c|c|c|}
\hline & Atos oficiais da CPLP & Registros na Folha de S. Paulo & Registros em O Globo \\
\hline $\mathbf{1 9 9 6}$ & 08 & 09 & 10 \\
\hline $\mathbf{1 9 9 7}$ & 09 & 01 & 04 \\
\hline $\mathbf{1 9 9 8}$ & 13 & 07 & 07 \\
\hline $\mathbf{1 9 9 9}$ & 08 & 02 & 07 \\
\hline $\mathbf{2 0 0 0}$ & 15 & 03 & 05 \\
\hline $\mathbf{2 0 0 1}$ & 12 & 02 & 02 \\
\hline $\mathbf{2 0 0 2}$ & 18 & 03 & 03 \\
\hline $\mathbf{2 0 0 3}$ & 16 & 05 & 02 \\
\hline $\mathbf{2 0 0 4}$ & 23 & 06 & 06 \\
\hline $\mathbf{2 0 0 5}$ & 29 & 00 & 04 \\
\hline TOTAL & 151 & 38 & 50 \\
\hline
\end{tabular}

Fonte: Pesquisa nos acervos dos jornais e em 18 anos CPLP: os desafios do futuro

Apenas no primeiro ano de criação da CPLP há uma equivalência entre o número de atos oficiais da entidade e a quantidade de registros nos jornais, talvez, em razão da novidade. No entanto, logo no ano seguinte e nos demais subsequentes, essa comunidade ficou esquecida. Não discutimos se os registros da CPLP são os mesmos dos jornais. Utilizamos os dados oficiais das atividades da comunidade para revelar a existência da possibilidade de ações noticiáveis e propor uma comparação. Em 1999, por exemplo, a CPLP teve 8 atos oficiais, entre eles a de uma missão para acompanhar o referendo sobre a independência de Timor-Leste. Naquele ano, a Folha apresenta dois registros fora da agenda da CPLP. Um é a ida do presidente FHC a Lisboa, e o outro é uma entrevista com os escritores Mia Couto (Moçambique) e Pepetela (Angola).

Diante desses dados, sugerimos pensar na invisibilização por ausência da CPLP, uma ação que não possibilita enxergar o Brasil como membro dessa comunidade, confirmando uma não-noticiabilidade. De fato, há uma série de assuntos e questões que não encontrou lugar nos critérios para que se tornassem notícia. Em razão dos múltiplos traços comuns, das relações 
históricas e identitárias, poder-se-ia esperar que temas da CPLP tivessem alguma relevância e proximidade aos brasileiros, mas o que se percebeu foi silenciamento. Os poucos registros dizem da "presença de uma ausência". Sugerimos que essa memória oculta tenha relação com a história e que passa pelo jornalismo sem muita percepção. Assim, buscamos analisar, além dos números, os poucos registros sobre a CPLP nesses jornais.

\section{Para além dos números: histórias, memórias e identidades em jogo}

Quando tratamos de memória lidamos com lembranças e esquecimentos que, em nosso caso, entrelaçam-se ao jornalismo. Da memória, pontuamos que é o recordar deliberado, o processo de construção de elos entre passado e futuro. Lembra Nunes (1988: 29) que, "pela mediação do passado, o presente e o futuro se vinculam à tríade dos antecessores dos contemporâneos e dos pósteros". Além disso, não há fronteiras entre memória individual e coletiva, embora esta última "extraia sua força e duração do fato de que um conjunto de homens the serve de suporte, são indivíduos que se lembram enquanto membros de grupos" (Ricoeur, 2008: 133).

Nossa atenção está voltada para a memória social, entendida como uma coletânea de "rastros deixados pelos acontecimentos que afetaram o curso da história dos grupos envolvidos, e que se the reconhece o poder de encenar essas lembranças comuns por ocasião de festas, ritos, celebrações públicas" (Ricoeur, 2008: 129). Assim, o conjunto dos poucos registros sobre a CPLP nesses dez anos emerge como uma coletânea de rastros que vai constituir nossas lembranças/esquecimentos.

Pollak (1992) assegura que a memória social é fenômeno seletivo, instável e submetido a jogos de poder. "A memória nacional constitui um objeto de disputa importante, e são comuns os conflitos para determinar que datas e que acontecimentos vão ser gravados na memória do povo" (Pollak, 1992: 204). Os eventos serão esquecidos ou lembrados em razão dessas tensões. Por isso, recordar e esquecer são uma mesma plataforma. Afirma Ricoeur (2008: 435): "o esquecimento comum está, sob esse aspecto, do mesmo lado silencioso que a memória comum". Festejar a memória é, ao mesmo tempo, um ritual solene de esquecimento e que interdita o "acesso aos tesouros enterrados da memória" (Ricoeur, 2008: 452).

Fica patente que a memória não surge como um truque de mágica. Ela utiliza-se da função mediadora das narrativas, porque é impossível lembrar e narrar tudo e sobre tudo. É exatamente essa condição que será utilizada para omitir e manipular.

"As estratégias do esquecimento enxertam-se diretamente nesse trabalho de configuração: pode-se sempre narrar de outro modo, suprimindo, deslocando as ênfases, refigurando diferentemente os protagonistas da ação assim como os contornos dela. Para quem atravessou todas as camadas de figuração e refiguração narrativa desde a constituição da identidade pessoal até a das identidades comunitárias que estruturam nossos vínculos de pertencimento, o perigo maior, no fim do percurso, está no manejo da história autorizada, imposta, celebrada, comemorada - da história oficial" (Ricoeur, 2008: 455). 
Também Le Goff (1990) empresta à memória importância nas lutas pelo poder. "Tornarem-se senhores da memória e do esquecimento é uma das grandes preocupações das classes, dos grupos, dos indivíduos que dominaram e dominam as sociedades históricas" (Le Goff, 1990: 426). Segundo esse autor, esquecimentos e silenciamentos da história revelam os mecanismos de manipulação da memória. Para Cunha (2006: 83), a memória é "um campo de disputa, passando o controle social e mesmo o exercício do poder, pela capacidade de definir o memorável e o que deve ser esquecido". É o que também diz Halbwachs (1990) ao sustentar que somos arrastados em múltiplas direções, mas a memória será a referência de segurança.

Quais são as memórias que estão em jogo na Folha de S. Paulo e em O Globo sobre a CPLP? Metodologicamente, um caminho para a resposta é o da análise crítica da história. 0 Brasil, por exemplo, foi incluído no mapa do mundo no século XVI e, para Furtado (2007), isso se deu em razão da expansão mercantil europeia. A imposição desse destino - ser lugar de exploração - norteou as ideias de um Brasil, que só nasce tardiamente no século XIX. No longo período de não-nação e, até depois, fomos o outro, uma colônia portuguesa com significativa presença predatória também de ingleses, franceses, holandeses. As massas de gente inseridas no Brasil participam dessa violenta lógica da exploração. Assim, boa parte das nossas relações humanas foram submetidas a esse quadro, com reflexos na construção identitária.

Em 1808, com a fuga da corte portuguesa ao Brasil e, depois, com a Independência, a referência identitária da nova nação será europeia, cabendo a elite luso-brasileira desenvolver o caráter nacional, ou seja, um tipo ideal: homem, branco, culto, cordial. Essa linha de força identitária, que envolveu a construção do país, fixou o outro nesse mesmo território. Esse diferente é o negro, pobre, crioulo, africano, brasileiro africanizado, malandro, preguiçoso, que carrega uma brasilidade maldita e que explicaria, para a elite, nosso atraso. Basta lembrar as teses de negros como criminosos natos e da imigração nórdica para "embranquecer" o país ${ }^{50}$.

Imagina-se uma síntese de identidade nacional, fabricada em sentidos entrelaçados: acertar os passos com a civilização europeia, branca, do colonizador e, ao mesmo tempo, apagar traços identitários com negros africanos e índios. A ideia de povo brasileiro, que se configura como memória social nacional, por exemplo, com o mito da "união harmoniosa das três raças", é uma das matrizes que busca apagar e marcar étnica e racialmente os negros como outros a serem excluídos. As grandes narrativas históricas dominantes vão tentar conduzir a construção identitária nacional, que

"pressupõe apagar algo que positivamente existia (a violência da colonização, o sistema escravagista e a multidão de negros que povoavam o país) e, ao mesmo tempo, pressupõe criar algo que positivamente nunca existiu: o consórcio harmonioso entre colonizador e o habitante natural da terra, o reconhecimento da resistência

50 Mais em RODRIgUeS, N. (1957) As raças humanas. São Paulo: Progresso; FREYRE, G. (1946) Casa Grande \& Senzala. Rio de Janeiro: José Olympio; ROMERO, S. (1943) História da literatura brasileira. Rio de Janeiro: José Olympio; e outros. 
heróica das culturas autóctones, a convergência entre valores nativos e os valores da civilização ocidental" (Cunha, 2006: 101).

É preciso registrar dois aspectos históricos que têm influência nos processos identitários e que envolvem os países da CPLP. O primeiro é que o Brasil é uma das últimas nações a encerrar a escravidão negra. Nas vésperas do século $\mathrm{XX}$, muitos de nós eram "seres sem alma", como negros e índios eram tratados. São 320 anos de um dos mais perversos sistemas escravocratas e isso não vai passar incólume na memória social e nem na construção das identidades. O segundo é que os países africanos que foram colônias portuguesas só deixaram essa condição há menos de 40 anos. Só em 1975 Moçambique ganha independência.

Temos, assim, um quadro que fixa papeis de civilização e desenvolvimento na Europa, e de primitivismo e pobreza nas ex-colônias, construção que se espraia pelo jornalismo até as raízes mais profundas da formação das nações da CPLP. Para Sodré, no Brasil ainda persiste a utopia civilizatória europeia, que continua "a reproduzir o discurso de enaltecimento do seu valor universalista, como garantia da colonialidade do poder" (Sodré, 1999:33).

$\mathrm{Na}$ investigação sobre a CPLP nos jornais Folha de S. Paulo e O Globo, os rastros fazem emergir memórias e identidades que põem nas sombras as raízes dos países da comunidade; mas também revelam brechas por onde se pode criticar ao neocolonialismo e as tentativas de apagar, principalmente os negros, da constituição do Brasil nação. Não é demais relembrar que, dos nove países da CPLP, seis deles são africanos e considerados pobres.

Na Folha e no O Globo no dia 16/07/1996, por exemplo, véspera da criação da CPLP, o presidente Fernando Henrique Cardoso concedeu entrevista ao Diário de Notícias, de Lisboa. Os dois jornais brasileiros a reproduziram. Em O Globo (O País, p. 3), o presidente FHC afirma que a "mentalidade caipira e provinciana" do brasileiro "rejeita a globalização" (Figura 1). Na sequência, ele explica-se que essa "rejeição", que nosso "atraso civilizacional" é decorrente de nossa "mentalidade caipira e provinciana", "sem dúvida nenhuma, variante da mentalidade criolla". Ou seja, ele convoca memórias, histórias e identidades. 
Figura 1 - Recorte de parte da notícia em O Globo



Fonte: acervo do jornal O Globo (O País, 16/07/1996, p. 3)

Essa notícia faz emergir rastros de um ângulo de compreensão sobre o processo de formação do povo brasileiro, revelando uma presença constitutiva dos negros e crioulos, e que são incômodos às elites, das quais os jornais são guardiões de seus interesses. Essas pistas podem convocar desde um imaginário do apagamento da barbárie da escravidão até propor, como memória prospectiva, o imaginário da limpeza étnico-racial, para que o Brasil possa acertar os passos com a civilização globalizada. As dimensões identitárias envolvidas no evento da criação da CPLP parece está a serviço de uma memória, por vezes oculta e manipulada, revelando-se uma sutil disputa entre o que se deve lembrar e o que se deve esquecer.

Nesse sentido, o jornalismo é sinalizador de como o passado é relembrado e de como deve ser esquecido. Há um compromisso quase imperceptível com os ditos memoráveis e, ao mesmo tempo, com os silenciamentos. Por isso, a experiência jornalística

"não pode ser explicada e explorada unicamente a partir da face mais visível de seus produtos. É preciso apanhá-la entre um direito e avessos. Por esse caminho é possível indicar que as várias experiências estão intimamente conectadas com outras tessituras e, nesse sentido, necessariamente imbricadas na escrita dos acontecimentos jornalísticos" (Fonseca, 2014: 26).

De maneira geral, a Folha e $O$ Globo, quando registram a CPLP, fazem-na revelando um organismo sem expressão econômica, política e diplomática, talvez em razão também do modo como o próprio governo brasileiro a percebe. As notícias giram em torno da relação de alinhamento entre Portugal e Brasil, nações que agem como "senhores" dos destinos dos países africanos pobres, doentes e entregues a corrupção e ditaduras. Em O Globo (O País, p. 8), o presidente Lula diz que a CPLP é uma "mostra do quanto Portugal e Brasil podem realizar juntos. Afinal, não nos faltam o que poderiam chamar de vantagens comparativas - a língua, a 
cultura, a afinidade natural". A Folha e $O$ Globo até chegam a reconhecer uma relação de parentesco entre Brasil e África, mas apenas para fixar as diferenças, fixando os países africanos como os "primos pobres dos brasileiros" (Figura 2).

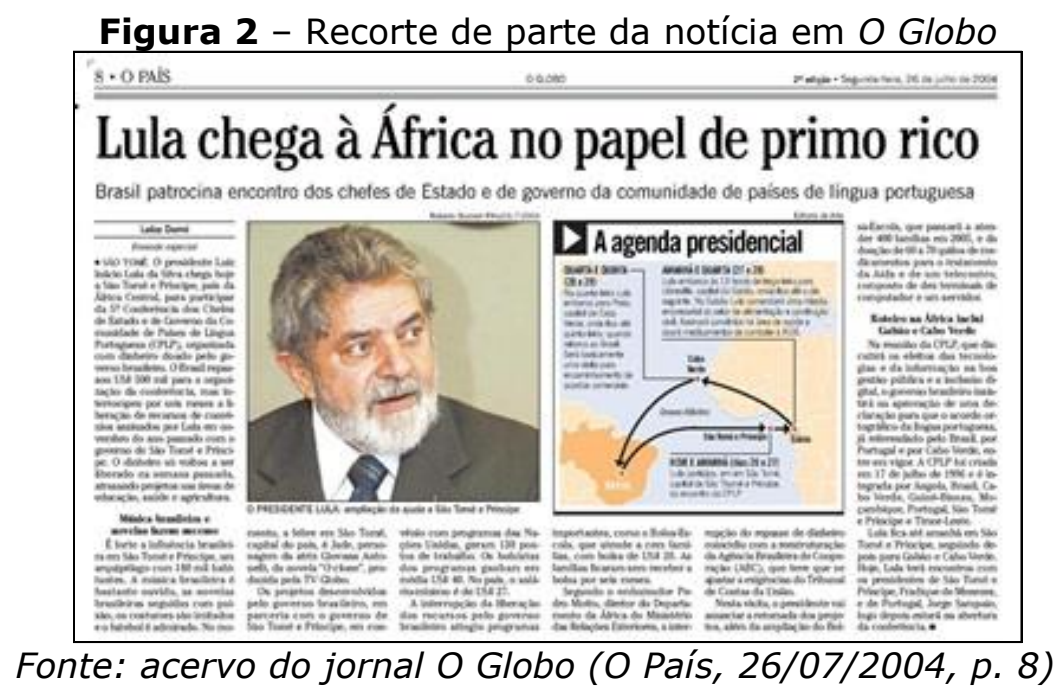

Em 13/04/1999, a Folha (Brasil, p. 6) trata da ida do presidente FHC a Lisboa. Afirma o texto: "A visita a Portugal seria mais de compadrio, dado o relacionamento histórico entre os dois países". Lembra ainda o jornal: "A CPLP, que reúne, além de Brasil e Portugal, as antigas colônias africanas de Portugal". Ou seja, apenas os africanos foram colônias portuguesas? O jornal esquece que o Brasil foi colônia e só lembra o "compadrio" com Portugal. Ao que parece, os critérios de noticiabilidade não são suficientes para dialogar com certas sutilezas que atravessam o jornalismo. Assim, regras e ações de rotina podem não alcançar o jornalismo como experiência múltipla, implicado no mundo, em temporalidades e historicidades, em meio a tensões que constroem e desconstroem o lembrar e o esquecer.

A Folha de S. Paulo, em 15/07/1997 (Figura 3) traz um único registro a lembrar o primeiro ano da criação da CPLP. E ele é exemplar. Informa o texto que os países africanos de língua portuguesa querem que o Brasil estenda a eles o mesmo direito de livre circulação concedido aos portugueses, que podem visitar o país sem a necessidade de obter visto nos consulados. Esse registro do jornal foi publicado exatamente na página policial. Ou seja, essa visibilização seletiva do medo-rejeição do outro aparece como rastros também em outras edições dos dois jornais, reforçando memórias. 
Figura 3 - Recorte de parte da notícia na Folha de S. Paulo



Fonte: acervo do jornal Folha (Cotidiano, 15/07/1997, p. 4)

Os jornais vão revelando, assim, uma não-noticiabilidade lusófona, seja pela ausência seja pelos poucos e contaminados registros de uma memória social ocultada e manipulada. Busca-se negar a condição histórica do Brasil como colônia e de encobrir o longo e violento processo de escravização. Dessa forma, não se reconhece a CPLP como uma comunidade, o que não deixar de ser uma posição identitária. De outro lado, e ao mesmo tempo, os poucos registros deixam escapar a construção de uma memória racista, que reafirma uma ancoragem eurocêntrica, de uma globalização pelo alto, indo da indiferença até a repulsa diante do outro que nos constitui profundamente.

\section{Jornalismo: agente e forma da memória}

Nosso percurso já indicou o jornalismo como dispositivo que faz lembrar e faz esquecer. Para Kitch (2008), o jornalismo é espaço de construção da memória, não atuando somente em eventos de impacto, datas cívicas, mas também no cotidiano. "A construção da memória social é um processo de longo prazo, de um tecer de pequenos momentos" (Kitch, 2008: 313), o que nos remete a coletânea de rastros.

Essa autora alerta que recebemos, simultaneamente, as informações e as formas de memória de várias fontes e não apenas da mídia, isto é, "estamos todos na mesma sopa da memória e, seus ingredientes, não vêm do jornalismo sozinho" (Kitch, 2008: 316). Ele não é o canal para a memória, mas forma e local de construção dela. Ao não atuar de forma exclusiva, o jornalismo se associa a outros dispositivos culturais, políticos, econômicos, educacionais, ou seja, "forma uma rede de memória que se liga a outras redes" (Kitch, 2008: 317).

$\mathrm{Na}$ investigação sobre os registros dos dez primeiros anos da CPLP na Folha e em $O$ Globo, o jornalismo constitui-se em agente da memória social, articulando o silenciamento temático, longo e persistente, a uma memória manipulada, a partir dos rastros identificados. Essa constatação nos faz transitar da memória-passado à memória-prospectiva. O jornalismo 
maneja a ressignificação do passado domesticado e, ao mesmo tempo, aponta-nos um devir que também deve ser lembrado.

Ora, se não tomarmos conhecimento da existência de eventos ao longo do tempo e de forma regular, nenhum recordar vai se institui, porque o nada não emerge. Essa memória ausente, no jornalismo, é parte da construção do esquecimento. Mesmo as raras notícias diluídas no emaranhado jornalístico fazem parte desse processo, no entanto, elas são rastros que dizem de formas políticas, culturais, sociais. Eles se configuram com o todo disponível, convertendo-se em uma memória obrigada.

Quando jornalistas se debruçam sobre acontecimentos que podem se tornar notícias, a exemplo da CPLP, parece incontornável não considerar as relações do passado entre Portugal e as suas ex-colônias na América, África e Ásia, mesmo que os jornalistas não tenham consciência de que estão num jogo entre o lembrar e o esquecer. Halbwachs (1990: 49) usa da metáfora dos "fios muito finos e entrelaçados" para explicar as temporalidades na construção de nossa memória. O jornalismo participa de alguma forma dessa tessitura que nos constitui.

Os exemplos das notícias nesse artigo revelam a articulação entre jornalismo, memórias e identidades. Em O Globo e na Folha (16/07/1996), quando o presidente FHC afirma que o "brasileiro pensa como caipira" emergem memórias retrospectivas, do Brasil colônia e, ao mesmo tempo, memórias prospectivas, que apontam o caminho que o país deve adotar para acertar os passos com a civilização, ou seja, apagando a "mentalidade crioula". Em O Globo (26/07/2004), quando o presidente Lula diz que, através da CPLP, "o Brasil e Portugal podem realizar juntos" por conta da "língua, cultura, afinidade natural", articula-se passado e devir.

Esse trabalho retrospectivo e prospectivo é nítido na Folha, em 18/07/2000 (Figura 4): "De uma só vez, FHC mandou recados para dissidentes políticos de Angola, cobrou união do grupo para enfrentar os efeitos da globalização, estabeleceu prioridades ao desenvolvimento comum, distribuiu verbas para treinamento de pessoal e disponibilizou tecnologia".

Figura 4 - Recorte de parte da notícia na Folha de S. Paulo

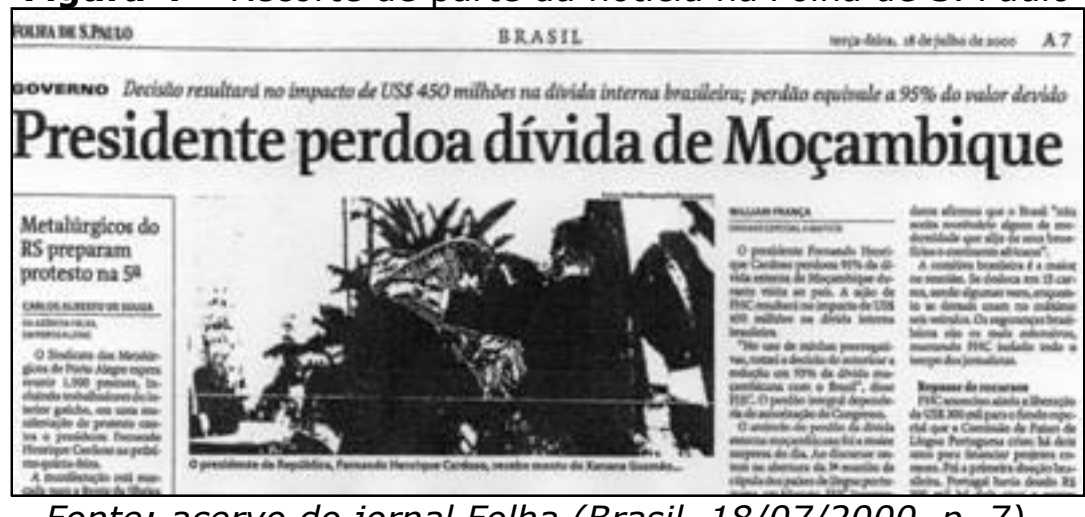

Fonte: acervo do jornal Folha (Brasil, 18/07/2000, p. 7) 
Sugerimos que a CPLP, seja pela invisibilização ou pelos poucos registros, alimenta uma memória coletiva. "Isso não implica pressupor que as memórias sejam uniformes dentro de um determinado grupo social, uma vez que cada pessoa recorda fatos diferentes em função de suas trajetórias e vivências pessoais" (Cabecinhas, 2011: 174). Compreendemos que há fios de significação persistentes a atravessar os arranjos sociais e, apesar do tempo "pós-colonial", a descolonização parece não estar sepultada. Entre nós, visões de um mundo eurocêntrico ainda perduram (Sodré, 1999).

Percebemos uma relação de mútua exigência: o jornalismo necessita da memória para se posicionar e recontar os eventos. E a "memória precisa do jornalismo para fornecer um dos projetos mais comuns do passado" (Zelizer, 2008: 79). Para essa autora, os jornalistas não se reconhecem colaboradores na construção da memória porque são "fornecedores do presente", e assim desprezam as relações com o passado. "O presente tornou-se horizonte. Sem futuro e sem passado, ele [o presente] produz diariamente o passado e o futuro de que sempre precisa, um dia após o outro, e valoriza o imediato" (Hartog, 2013: 148).

No jornalismo, a memória não é parâmetro ou critério nas notícias. No entanto, defende Zelizer (2008: 81) que "jornalismo e jornalistas são um local não óbvio, mas fértil de memória, e seu status como agentes de memória precisa ser melhor compreendido". Acredita essa autora que a memória para os jornalistas dá sentido ao presente, "constrói conexões, sugere inferências, cria estacas de história, age como bitolas para medir a magnitude e impacto de um evento, oferece analogias e fornece curtas explicações" (Zelizer, 2008: 82). Assim, o passado é um rico repositório presente na vida dos jornalistas, na medida em que ele "oferece um ponto de comparação, uma oportunidade para a analogia, um convite à nostalgia e uma reparação aos eventos anteriores" (Zelizer, 2008: 82). Mas a autora não esquece que a memória traz um compromisso, na maioria das vezes obscurecido, com o não lembrar.

\section{(Em) conclusão}

O levantamento dos registros nos dez primeiros anos da CPLP na Folha de S. Paulo e em $O$ Globo é parte de uma longa investigação ${ }^{51}$ que nos possibilita observar o processo de construção da memória dessa comunidade. Há uma discussão de fundo identitário. Chamamos atenção que nem a memória nem as identidades a atravessar o jornalismo emergem como critérios de noticiabilidade, mas são convocadas a propor interpretações, a produzir sentidos, a organizar, mesmo que sutilmente, um tipo de visão de mundo. Usos e abusos da memória pelo jornalismo conformam a não-noticiabilidade, o que não implica vazio, mas um campo aberto, tenso, fértil e inacabado que pode revelar a manipulação das memórias/esquecimentos.

Os poucos registros encontrados são rastros que denunciam um silenciamento e que, em grande medida, dizem das relações identitárias que se tecem historicamente entre o Brasil

51 A pesquisa completa, que é objeto do Doutorado na Comunicação da UFMG, objetiva investigar os 20 anos na CPLP a partir dos jornais Folha de S. Paulo e O Globo. Ela será concluída em dezembro de 2017. 
e as demais nações da CPLP. Os elos entre nós são incontornáveis, porém, para os jornais, eles não são reconhecidos como noticiáveis. Assim, sugerimos pensar o jornalismo como dispositivo identitário, como agente e forma de memória, que atua como um domesticador retrospectivo e prospectivo do lembrar e do esquecer.

A coletânea dos rastros permite observar um processo de construção, de ressignificação e de persistência de uma lógica que faz emergir a notícia como meio de memória manipulada, em razão do seu modo de dizer sobre a CPLP, configurando-se nas superfícies impressas com um dito sobre uma não-comunidade. A busca por esse fenômeno deságua na análise critica da história, em que se denuncia a tentativa de apagamento como uma ação identitária, em razão da comunidade dos povos de língua portuguesa ser majoritariamente negra e africana.

\section{Referências}

ARBEX JR. José. (2001). Showrnalismo: a notícia como espetáculo. São Paulo: Casa Amarela. CABECINHAS, Rosa. (2011). Narrativas identitárias e memória social: estudos comparativos em contexto lusófono. In: GAMA, Jaime et al. (Coord.) Cultura Portuguesa, Interculturalidade e Lusofonia. Braga: Universidade Católica Portuguesa, pp. 171-184.

CABECINHA, Rosa et al. (2006). Identidades nacionais e memória social: hegemonia e polêmica nas representações sociais da história. In: MIRANDA, J. e JOÃO, M. I. (Eds.). Identidades Nacionais em Debate, Oeiras: Celta, 2006, pp. 67-92.

CUNHA, Eneida L. (2006). Estampas do imaginário: literatura, história e identidade cultural. Belo Horizonte: UFMG, 2006.

ETTEMA, James. S. \& GLASSER, Theodore. L. (2011). A íntima dependência mútua entre fato e valor. Revista Brasileira de Ciência Política, n. 6, pp. 249-276.

FONSECA, Ana C. S. (2014). É tudo mesmo jornalismo? In: LEAL, Bruno. S. et al (Orgs.). Para entender o jornalismo. Belo Horizonte: Autêntica, pp. 19-28.

FRANCISCATO, Carlos E. (2014). Limites teóricos e metodológicos nos estudos sobre a noticiabilidade. In: SILVA, Gislene et al. (Orgs.). Critérios de noticiabilidade: problemas conceituais e aplicações. Florianópolis: Insular, pp. 85-113.

FURTADO, Celso. (2007). Formação econômica do Brasil. 34a ed. São Paulo: Companhia das Letras.

HALBWACHS, Maurice (1990). A memória coletiva. São Paulo, Vértice.

HARTOG, François. (2013). Regimes de historicidade. Belo Horizonte: Autêntica.

ILHARCO, Antônio \& MURARGY, Murade. (2014). 18 anos CPLP: os desafios do futuro. Lisboa: Ed. Sersilito.

KITCH, Carolyn. (2008). Placing journalism inside memory - and memory studies. Memory Studies, v 1, n 3, Reino Unido, pp. 311-320.

LE GOFF, Jacques. (1990). História e memória. Campinas/SP: Ed. Unicamp.

MAFRA, Renan. L. M. (2014). Tudo é notícia? In: In: LEAL, Bruno. S. et al (Orgs.). Para entender o jornalismo. Belo Horizonte: Autêntica, pp. 103-118. 
MOTTA, Luiz G. (2014). Apresentação. In: LEAL, Bruno. S. et al (Orgs.). Para entender o jornalismo. Belo Horizonte: Autêntica.

MOUILLAUD, Maurice. (1997). O jornal: da forma ao sentido. Brasília: Editora UnB.

NUNES, Benedito. (1988). Narrativa histórica e narrativa ficcional. In RIEDEL, D. C. (Org.). Narrativa, ficção e história. Rio de Janeiro: Imago.

POLLAK, Michael. (1992). Memória e identidade social. Estudos Históricos, v 5, n. 10. Rio de Janeiro, pp. 200-212.

RICOEUR, Paul. (2008). A memória, a história, o esquecimento. Campinas: Ed. Unicamp.

SHOEMAKER. Pâmela. (2014). Prefácio. In SILVA, Gislene et al (Orgs.). Critérios de noticiabilidade: problemas conceituais e aplicações. Florianópolis: Insular.

SILVA, Gislene. (2014). Pensar critérios de noticiabilidade. In: SILVA, Gislene et al (Orgs.). Critérios de noticiabilidade: problemas conceituais e aplicações. Florianópolis: Insular, pp. 51-69.

SODRÉ, Muniz. (1999). Claros e escuros: identidade, povo e mídia no Brasil. Petrópolis/RJ: Vozes.

ZELIZER, Barbie. (2008). Why memory's work on journalism does not reflect journalism's work on memory. Memory Studies, v. 1 n. 1. Reino Unido, pp.79-87. 